\title{
Challenges in Serving Rural American Children through the Summer Food Service Program
}

\author{
BARBARA WAUCHOPE AND NENA STRACUZZI
}

$\mathrm{M}$ any families rely on U.S. Department of Agriculture (USDA)-funded school lunch and breakfast programs to make the family's food budget stretch, improving their food security throughout the school year. These programs feed about 31 million students annually. ${ }^{1}$ During the summer where schools are not in session, food security decreases. ${ }^{2}$ The USDA developed the Summer Food Service Program (SFSP) to address this problem. The SFSP funds state administrators who contract with local sponsors, typically schools, nonprofit organizations, summer camps, and local government agencies to provide meals to low-income children. ${ }^{3}$ These meals, along with summertime school lunches, where available, have been found to reduce the prevalence of food insecurity. ${ }^{4}$

For families living in rural America, rates of poverty and food insecurity are among the highest in the country, ${ }^{5}$ yet of all the SFSP sites, less than one-third are located in rural communities. ${ }^{6}$ Not only can fewer rural children participate in the summer programs, but even when the programs are available, rural children participate less than children in more urban areas. ${ }^{7}$ This brief outlines the results of an exploratory study of potential barriers to locating more programs in rural areas through sponsorship and to participation in those programs by rural children.

\section{Program Requirements Inhibit Rural Participation}

One explanation for low enrollment in SFSP is the lack of rural sites. Sponsors prefer operating programs as "open sites," which are locations like parks or schools where any child can go to obtain a free meal. However, to run an open site more than one-half of the children in the local school's attendance area must be eligible for free or reduced price meals during the school year. Open sites represent 83 percent of the SFSP locations and are popular because they do not limit children's

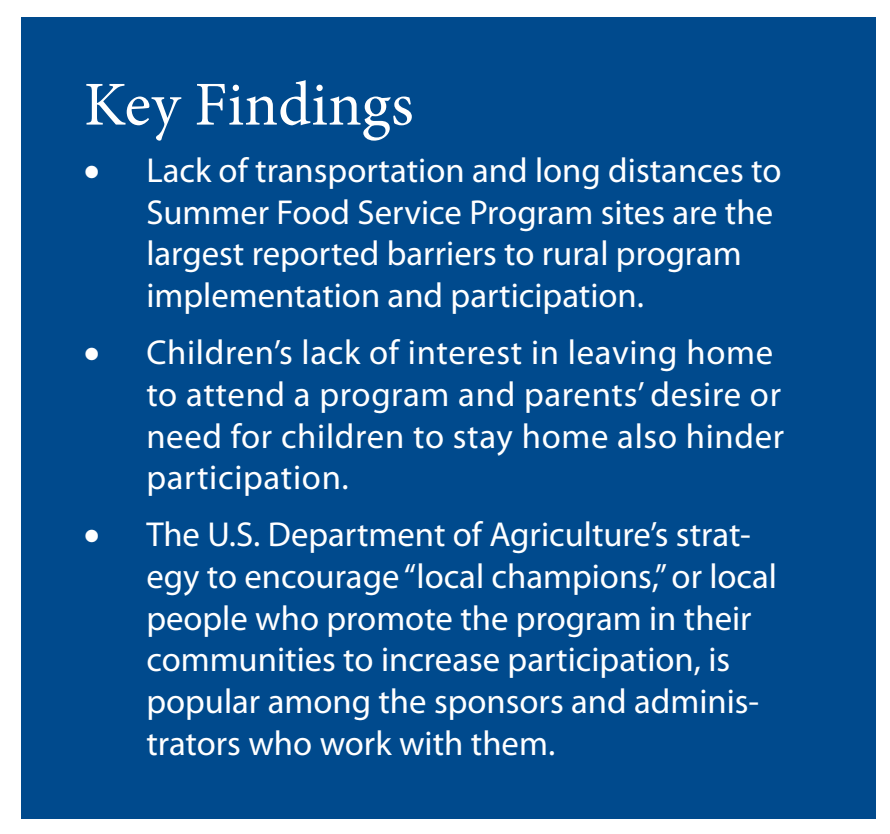

participation in the way a site that requires enrollment in a formal program does. ${ }^{9}$ However, in rural areas children are not geographically concentrated so school districts often cannot meet the 50 percent requirement. ${ }^{10}$ Finding potential sponsors for either open or enrolled sites in rural communities is difficult for a variety of reasons, including the challenges and costs inherent in transporting food and/or children. ${ }^{11}$

Congress and the USDA have made changes to the SFSP to make it easier for sponsors to establish and operate sites, thus increasing access. Delivering meals to children rather than requiring them to come to fixed sites is now allowed, for example. Paperwork requirements have also been eased through the Simplified Summer Food Program, and a "Seamless Summer Food Waiver" was created that allows school districts to administer the program as a continuation of the National School Lunch Program. ${ }^{12}$ 
These changes notwithstanding, transportation issueseither to deliver meals to children or to bring the children to sites-remain the most common barrier to participation in rural areas. ${ }^{13}$ In 2004, Congress attempted to remedy this problem by establishing the Rural Transportation Grant program to fund "innovative approaches to limited transportation in rural areas." 14 Over three years, the government awarded thirty-six grants with mixed results. The USDA report concluded that transportation grants were a "highly cost inefficient method of ongoing support for SFSP in rural areas" because low participation or low concentrations of children could not produce the economies of scale needed to make the programs financially viable. ${ }^{15}$ However, for many grantees, failure to meet program targets was due to program organization and delivery problems, not transportation. Also, a number of program grantees did succeed in achieving meal cost efficiencies by offering appealing activities or food that attracted children to these rural sites. Nonetheless, the USDA recommended against continuing the grants in 2009 .

To gain a deeper understanding of barriers to participation among rural providers and the children they serve, researchers at the Carsey Institute interviewed a small group of eight SFSP state administrators and twenty-three sponsors in January 2010. Following the interviews, researchers surveyed a group of SFSP state administrators and a group of sponsors working in rural counties to look at the relative importance of a set of issues raised in the interviews and from the two different perspectives. The state administrators were asked about the challenges of both recruiting sponsors and attracting children to the program. Sponsors were also asked about barriers to children's participation and about barriers to program implementation.

\section{Transportation Issues Remain the Largest Barriers}

As expected, study participants rated transportation issues such as long travel distances, lack of options for transporting meals or children, or high costs of gas and maintenance as large or moderate barriers to both program implementation and to children's participation in SFSP. ${ }^{16} \quad$ Fourteen of the twenty-three sponsors rated the lack of transportation options for children traveling to sites as the largest barrier to program startup and implementation. However, more than half did not rate any of the other transportation issues as implementation barriers. This result makes sense given that one must first have a mode of transportation before the cost of gas and vehicle maintenance and long distances become issues. The lack of transportation options for children traveling to sites was also frequently cited as the largest barrier to the children's par- ticipation in the SFSP. More than two-thirds of sponsors (68 percent) also said that the long distances children had to travel to the sites limited participation.

Most of the state administrators also rated lack of transportation options and distance as large or moderate barriers to participation, and they also included the lack of transportation options for delivering meals to children. More administrators than sponsors also rated the high cost of transportation (in gas and maintenance) as the largest barrier to implementation, specifically for recruiting sponsors.

\section{Population Density a Major Problem for Rural Implementation}

Fewer than half of the sponsors said that other issues unrelated to transportation were barriers to starting up and implementing the SFSP. However, among those who rated other issues as high on the list, the most common barrier to implementation was the limited concentration of children in rural areas. With so few children in an area, it was difficult to break even on the cost of the program. Other examples included the limited number of summer programs for children, including summer school, offered in rural areas and lack of local coordination and scheduling among the summer programs that do exist in rural areas. The latter problem results in too few children in the same place at the same time. Both situations, not necessarily unique to rural areas, limit the number of children available to be served by an SFSP and thus reduce the cost effectiveness of the program.

In contrast to the sponsors, most of the administrators rated a number of non-transportation issues as large or moderate barriers to program implementation, specifically sponsor recruitment. They viewed the problem of too few children in one place as a large or moderate barrier to implementation. However, most also said barriers included the lack of capacity among local organizations to prepare meals locally, lack of interest in sponsoring by local organizations capable of preparing meals (schools, for example), dislike of or discomfort with the accounting and paperwork required, and the high cost of the program overall. 


\section{Staying Home is a Barrier to Participation}

Two issues unrelated to transportation were children's lack of interest in leaving home to attend the program and parents' desire or need for children to stay at home. Both sponsors and administrators noted these two issues. Both issues suggest that families' perceptions of the appeal or benefits of the programs may be as important to children's participation as transportation. Administrators also included families' lack of awareness of SFSP and the lack of activities at program sites as barriers to participation. Several sponsors added that some children's programs or groups that care for more than a few children do not attend because they lack staff to supervise the children during the walk or drive to the program.

\section{Local Champions Help Rural Programs}

The USDA encourages local sponsors to recruit "local champions" or local people who promote the SFSP in their community as a strategy to build collaborations with local organizations and increase participation. The six sponsors who had local champions and six administrators who knew about them were enthusiastic about the strategy. They described a range of benefits, including talking with parents and increasing awareness of SFSP in communities, finding and persuading kids to come to the sites, coordinating volunteers and organizations, collaborating on program operation, providing outreach to potential sponsors, identifying sites with the greatest needs, and providing vision to the local program.

When asked for suggestions to improve rural programs, administrators (who were asked specifically about strategies to make it easier to recruit and maintain SFSP sponsors) recommended lowering the area eligibility requirement in the free and reduced lunch program to 40 percent, mandating school participation, and increasing the rural reimbursement rates and funding for transportation to sites and for home meal deliveries. Currently, sites are eligible only if 50 percent or more of the children in the area are eligible for free or reduced price meals.

Sponsors' suggestions targeted transportation. They included providing free, unlimited transportation to all children interested in attending; transportation options for children to and from homes; adding mobile sites that travel to the children; making it easier for programs like bookmobiles to deliver meals to homes; and providing more resources to pay for transportation overall. Adding or moving sites to reduce travel was another suggestion for increasing participation, as was decreasing area eligibility requirements to 40 percent and dropping income verification. Several sponsors suggested providing a meal to one parent as well as the child. Others recommended adding more activities to the program and more meals with fruits and vegetables. Increased resources for staff salaries and reimbursements were also recommended.

Finally, a handful of sponsors commented on the challenges of the SFSP program. One summed up their situation:

Most of the time, the rural sponsors have kind of a double whammy: they have limited funds available, they don't have many staff members, they don't have transportation to bring kids in when most of them live quite a ways out of town, and they don't have any funds for activities. Plus, they have a low number of kids, like 40 or 50 , so it is not economically feasible for them to operate a program.

Despite such challenges, most of the sponsors in the survey described only a few large barriers to either program operation or participation. For several, sponsoring a program has been a personally gratifying experience, stating that it was "the best experience of a lifetime ... great program ... great sponsors ... great volunteers," and "absolutely the most rewarding thing I've ever done ... four years of food, fun, fellowship! A terrific program.” 


\section{Conclusion}

Transporting meals to children or children to meals has always been and will continue to be the biggest challenge in operating Summer Food Service Programs in rural areas. SFSP state administrators and local sponsors we interviewed confirm that reality. Finding strategies to address the problem of distance and population density, respondents said, is key to successful startup and implementation, including recruiting and retaining the local sponsors who operate the program.

Lowering the area eligibility requirement from 50 percent to 40 percent is one possibility for expanding participation. This would increase the geographic areas eligible, opening the program to more families. However, allowing more families to be served would not necessarily change the number of families that participate if the number of sites remains the same.

Many of those interviewed suggested increasing modes of and funding for transportation. The USDA tried this with its Rural Transportation Grant program but concluded that the effort was too costly and inefficient. However, its findings may have been confounded by organization and program delivery factors affecting participation that were unrelated to transportation.

One of these factors is the extent to which SFSP sites appeal to families. Most SFSP sites have found that providing activities attracts participation. ${ }^{17}$ The combination of enrichment programming with meals can help low-income children overcome their tendency to fall behind their wealthier peers over summer vacation. ${ }^{18}$ More interesting programming, fresh and nutritious food, getting parents involved, and expanded marketing and outreach are all strategies that could bring more rural families into the program, particularly if combined with some help with transportation. To do this in rural areas, our respondents suggest, requires funding, support, and local collaboration. .

Increasing support for local sponsors and programs could also lead to new strategies to improve program participation if sponsors had a formal mechanism to share their innovations with one another. ${ }^{19}$ It also might be time for an effort by the SFSP to systematically identify programs in rural areas that are the most successful at attracting, engaging, and retaining both sponsors and children. A process for evaluating the programs and the characteristics of the most successful programs could help create an evidence-based SFSP model similar to the approach used in the fields of public health and criminal justice. These models could then be replicated by sponsors throughout rural America.

\section{Data and Samples}

The findings are drawn from a small exploratory study and are not representative of the attitudes, opinions, and perceptions of SFSP state administrators and sponsors nationally. The study was conducted using a voluntary online survey and telephone interviews with eight SFSP state administrators and a voluntary online survey of twenty-three sponsors of the SFSP in rural counties. Respondents were chosen from the ten states and twenty-six counties that are part of the Carsey Institute Community and Environment in Rural America long-term study of changing rural communities. Sponsors' experience ranged from one to thirty-five years, with half of the sponsors having worked as rural sponsors for five years or less. Nearly half (48 percent) of the sponsors were school districts, with the others evenly divided among private nonprofit organizations, community or faith-based organizations, local governments, college or universities, or state agency or migrant education programs. Sixty-one percent operated regular SFSP programs, and 27 percent operated their SFSP as the streamlined Simplified Summer Food Service Program or both. The majority operated their programs rather than contracting with vendors. 


\section{Endnotes}

1. USDA Food and Nutrition Service, National School Lunch Program Fact Sheet, http://www.fns.usda.gov/cnd/Lunch/ AboutLunch/NSLPFactSheet.pdf

2. M. Nord and K. Romig, Hunger in the Summer: Seasonal Food Insecurity and the National School Lunch and Summer Food Service Programs. (Washington, DC: USDA, Economic Research Service, 2006).

3. Meals are distributed through feeding sites operated by the sponsors. These sites are mainly two types: open feeding sites in which any child 18 years or younger can come and be served a free meal if the geographic area is within a school attendance area with 50 percent or more of the children eligible for free or reduced price meals, or enrolled sites at, for example, summer camps or municipal recreation programs, in which children can only participate if they are enrolled in the program and their family can demonstrate eligibility by submitting a household income application. Enrolled sites can turn into open sites; that is, any child in the program can receive the free meal if 50 percent or more of the applications show that the children are eligible for free or reduced price meals.

4. Ibid. Nord and Romig, Hunger in the Summer.

5. U.S. Bureau of the Census, Current Population Survey, Annual Social and Economic Supplements (2007), available at http://www.census.gov/hhes/www/poverty/histpov/ hstpov8.xls; U.S. Department of Agriculture, Household Food Security in the United States, Economic Research Reports, no. 11 (2004), no. 29 (2005), no. 49 (2006), and no. 66 (2007) (Washington, DC: USDA, Economic Research Service).

6. A. Gordon, et al., Feeding Low-Income Children When School Is Out-The Summer Food Service Program: Final Report. E-FAN-03-001 (Washington, DC: USDA Economic Research Service, 2003). In their study, they reported that the percentage of sponsors operating rural sites is between 23 and 33 percent.

7. USDA Food and Nutrition Service. Food That's In When School Is Out: Summer Food Service Program for Children: Rural Programs (Washington, DC: USDA Food and Nutrition Service, 1998), http://www.fns.usda.gov/cnd/ summer/library/rural2.pdf\#xml=http://65.216.150.153/texis/ search/pdfhi.txt?query=rural+participation + in + SFSP $\&$ pr $=F$ NS\&prox $=$ page\&rorder $=500 \&$ rprox $=500 \&$ rdfreq $=500 \&$ rwf req $=500 \&$ rlead $=500 \&$ rdepth $=0 \&$ sufs $=0 \&$ order $=$ r\&cq $=\& i d=$ 4 bc8d38338.

\section{Ibid. A. Gordon et al., Feeding Low-Income Children.}

9. Ibid.
10. A recent USDA-funded evaluation in rural Pennsylvania during the summers of 2005 and 2006 found that reducing the area eligibility requirement to 40 percent increased both the numbers of rural sites and sponsors, key factors in rates of children's participation. Advocates support changing the legislation to reduce the requirement to 40 percent, but so far the 50 percent requirement stands. See The Pennsylvania SFSP Rural Area Eligibility Pilot Evaluation Final Report (Washington, DC: USDA, February 2008). http://www.fns.usda.gov/oane/menu/Published/CNP/FILES/ PASFSPRuralPilot.pdf.

11. Ibid. A. Gordon et al., Feeding Low-Income Children.

12. USDA, "Summer Food Service Program, Program History," http://www.fns.usda.gov/cnd/Summer/about/ program_history.html.

13. Ibid. A. Gordon et al., Feeding Low-Income Children.

14. Child Nutrition and WIC Reauthorization Act of 2004, http://www.fns.usda.gov/cnd/Governance/Legislation/Historical/PL_108-265.pdf.

\section{USDA, Summer Food Service Program Rural}

Transportation Grants: 2009 Report to Congress, http://www. summerfood.usda.gov/library/RTGfinalreport.pdf.

16.Because this study was exploratory and not representative of the population of state administrators and program sponsors and because the sample sizes were so small, the percentages reported here should be interpreted as suggestive only.

17. Ibid. A. Gordon et al., Feeding Low-Income Children.

18. H. Cooper, et al.,"The Effects of Summer Vacation on Achievement Test Scores: A Narrative and Meta-Analytic Review," Review of Educational Research, Vol. 66, No. 3 (1996), 227-268.

19. The National Food Service Management Institute, the technical assistant provider to the federal meals programs, does provide a Web site for sharing information about programs. They conducted a brief survey of sponsors to identify programs with best practices resulting in a brief list published in a 2005 report: Overcoming Barriers to Participation in the Summer Food Service Program-An Identification of Best Practice Solutions (see http://www. nfsmi.org/documentlibraryfiles/PDF/20090901042814. pdf). However, this list, other resources on their Web site, and descriptions of the practices of a few programs on the USDA's Web site (see http://www.fns.usda.gov/cnd/summer/ States/program_access.html) do not address the issues specific to rural communities. 


\section{ACKNOWLEDGMENTS}

The authors wish to express our appreciation to the SFSP state administrators and sponsors who gave of their time to talk to us and respond to our survey. We also want to thank Barbara Ray at Hired Pen, Crystal FitzSimons at the Food Research and Action Center, and Beth Mattingly and Terri Rippett of the Carsey Institute for their helpful comments and suggestions.

\section{About the Authors}

Barbara A. Wauchope is director of evaluation and a research associate professor at the Carsey Institute at the University of New Hampshire (barb.wauchope@unh.edu).

Nena Stracuzzi is a research assistant professor at the Carsey Institute at the University of New Hampshire (nena.stracuzzi@unh.edu).

\section{ANIVERSITY}

Building knowledge for families and communities

The Carsey Institute conducts policy research on vulnerable children, youth, and families and on sustainable community development. We give policy makers and practitioners timely, independent resources to effect change in their communities.

This work was supported by the Annie E. Casey Foundation's initiative to strengthen rural families, the W.K. Kellogg Foundation, and an anonymous donor.

Huddleston Hall

73 Main Street

Durham, NH 03824

(603) $862-2821$

www.carseyinstitute.unh.edu 